\section{Discussion}

Though the use of mannitol intravenously has been extensively studied, little interest has been shown in its remarkable properties in the gut. Carr and Krantz (1953) showed that oral mannitol produced diarrhoea in rats; the mechanism has been partly elucidated by Hindle and Code (1962), who found that in the isolated duodenum of dogs hypertonic mannitol caused a profuse secretion of water and sodium into the lumen to produce an isosmotic solution. In the ileum this did not occur, and there was merely a slow absorption of both water and mannitol. The clinical use of osmotic diarrhoea has previously been made by Gertman et al. (1966) in treating ascites due to cirrhosis of the liver, and by Giovannetti et al. (1968), who used a sorbitol-mannitol mixture for correcting salt and water retention in uraemic patients.

As a $5.5 \%$ solution of mannitol is isosmotic with plasma the oral administration of 1 litre of $20 \%$ mannitol might be expected to produce almost 4 litres of diarrhoea fluid. There are, however, many variable factors such as absorption of mannitol from the gut, secretion of sodium into the gut, and perhaps inadequate time to achieve isosmolality. In practice, though the faecal volume varied considerably the mean of 2.9 litres was less than that predicted.

The commonest causes of failure were vomiting (due to too rapid ingestion of the mannitol) and failure of fluid restriction during the ensuing 24 hours. Abdominal colic and electrolyte disturbances did not occur; indeed, when hyponatraemia was present the serum sodium usually rose significantly (as shown in the Chart).

Oral mannitol should be used when diuretic therapy proves ineffective, particularly in the presence of hyponatraemia. In these circumstances it is used essentially as an alternative to peritoneal dialysis for those patients whose azotaemia is not severe enough to justify dialysis. Such patients include those incapacitated by congestive cardiac failure (Cases 1 and 2). It can be used in severe renal failure to correct overhydration (Case 3) and as a preliminary to infusion of sodium bicarbonate solution or blood (Case 4). Where the azotaemia itself is severe-for example, blood urea above $300 \mathrm{mg} . / 100 \mathrm{ml}$.dialysis is of course necessary.

\section{REFERENCES}

Carr, C. J. and Krantz, J. C., jun. (1938). Fournal of Biological Chemistry, 124, 221.

Gertman, P. M., Gagnon, O., and Iber, F. L. (1966). Fournal of the American Medical Association, 197, 257.

Giovannetti, S., Maggiore, Q., and Giusti, C. (1968). In Nutrition in Renal Disease, edited by G. M. Berlyne, p. 141. Edinburgh, Livingstone.

Hindle, W., and Code, C. F. (1962). American fournal of Physiology, 203, 215.

Maher, J. F., and Schreiner, G. E. (1965). Annals of Internal Medicine, 62,15 .

\title{
Impaired Glucose Tolerance : A Late Effect of Insulin Shock Treatment
}

\author{
RICHARD HUNTER,* M.D. ; MURIEL JONES, † M.B., PH.D. ; B. A. L. HURN, \\ CATHERINE DUNCAN, $\$ B.SC.
}

\begin{abstract}
Cummary: Glucose tolerance tests were performed in a $\checkmark$ group of patients in a mental hospital who had been treated with insulin shock and in a matched control group. Five out of $31(16 \%)$ patients in the insulintreated group and 1 out of $22(5 \%)$ controls had "diabetic" blood sugar curves. Median blood sugar values were significantly higher at 60 minutes and later in the insulin-treated group, as were mean blood sugar values when the "diabetic" patients were excluded. Small amounts of plasma insulin-binding antibody were found in two insulin-treated patients. In the absence of any other clear-cut explanation, it is suggested that in some patients massive doses of insulin by injection may leave diminished tissue responsiveness to insulin as a long-term after-effect.
\end{abstract}

\section{Introduction}

Insulin shock treatment (I.S.T.) as a method of reducing mental disturbance by the repeated induction of hypoglycaemic coma was introduced on a large scale in the 1930s (Wortis, 1959). It flourished again for a decade after the war, when

* Consultant Psychiatrist, Friern Hospital, London N.11.

† Senior Registrar, Exe Vale Hospital, Exminster, Devon.

$¥$ Clinical Pathologist, the Wellcome Research Laboratories, Bec'zenham, Kent.

$\int$ Member of Scientific Staff, M.R.C. Statistical Research and Services Unit, University College Hospital Medical School, London W.C.1. literally thousands of patients called "schizophrenic" were submitted to it. Though not "a cure," wrote Mayer-Gros3 (1953), a persistent advocate, “ it supports Nature's curative tendencies." Sakel (1956), its chief protagonist, explained that it acted by causing "an intensification of the tonus of the parasympathetic end of the autonomic nervous system, by blockading the nerve cell" (sic). This effect by "strengthening the anabolic force ... induces restoration of the normal function."

Many remained sceptical because of "the wide divergence in results reported by different investigators" (Jessner and Ryan, 1941). Others were soon convinced that its place in the treatment of "schizophrenia" was "firmly established" (Sargant and Slater, 1948). Opposing views were aired in the correspondence following the paper by Bourne (1953) under the title "The Insulin Myth." With the introduction of phenothiazine compounds discussion died down and soon insulin shock treatment, in all but a few isolated centres, was relegated to the limbo of psychiatric treatments which were supposed to have worked.

Insulin shock treatment consisted in giving daily intramuscular injections of crystalline insulin after overnight fast on five or six days a week, starting with a small dose and increasing until hypoglycaemic coma was induced. The dose was then adjusted to make coma last half to one hour. Patients were resuscitated by gastric or intravenous infusion of sugar: 
this was followed by a large carbohydrate-rich meal. The number of comas in one course of insulin shock treatment varied from 20 to 50 or even more. Most patients were given 45 comas. In practice this amounted to patients receiving extraneous insulin over two to three months in doses of hundreds, even thousands, of units at a time. Some were also given concomitant courses of electric convulsion shocks (E.C.T.) to supplement the frequently occurring hypoglycaemic fits. Considerable weight gain was the rule.

As early as 1938 Banting et al. wondered whether such a grossly antiphysiological regimen might not have repercussions on the regulation of carbohydrate metabolism outlasting the actual period of insulin administration. Our own interest in the possible long-term effects of insulin shock treatment was roused when we observed a 39-year-old man suffering from diabetes mellitus who during two admissions to a mental hospital 15 and 12 years previously had received courses of this treatment. It may be added that he had survived an episode of prolonged coma-a well-recognized hazard of insulin shock treatment-with permanent intellectual impairment. No history of diabetes or related disorders in his family was obtainable.

To find out whether this was a chance observation or whether disorders of carbohydrate metabolism were in fact commoner among insulin-treated patients, we performed glucose tolerance tests, assays of insulin-binding antibody, and estimations of plasma insulin levels in a group of such patients and a control group matched for age, sex, type of psychiatric disorder, height, weight, and length of hospital stay. None had been previously investigated for possible disordered carbohydrate metabolism.

\section{Material}

The insulin shock treatment group consisted of 31 patients (23 men, 8 women) and the control group of 22 (17 men, 5 women) resident in a psychiatric hospital. Comparison of the two groups in mean age, height, weight, and duration of stay in hospital is shown in Table I. None of these showed an

TABle I.-Age, Height, Weight, and Duration of Hospital Stay

\begin{tabular}{|c|c|c|c|c|}
\hline & Group & Mean & $\begin{array}{l}\text { Standard } \\
\text { Deviation }\end{array}$ & Range \\
\hline Age in years .. & $\begin{array}{l}\text { I.S.T. } \\
\text { Control }\end{array}$ & $\begin{array}{l}42 \cdot 5 \\
45 \cdot 8\end{array}$ & $\begin{array}{r}6 \cdot 6 \\
10 \cdot 9\end{array}$ & $\begin{array}{l}26-65 \\
22-65\end{array}$ \\
\hline Height in inches & $\begin{array}{l}\text { I.S.T. } \\
\text { Control }\end{array}$ & $\begin{array}{l}66 \cdot 4 \\
66 \cdot 0\end{array}$ & $\begin{array}{l}3 \cdot 2 \\
3 \cdot 6\end{array}$ & $\begin{array}{l}60-74 \\
59-72\end{array}$ \\
\hline Weight in lb $\ldots$ & $\begin{array}{l}\text { I.S.T. } \\
\text { Control }\end{array}$ & $\begin{array}{l}141 \cdot 8 \\
139 \cdot 3\end{array}$ & $\begin{array}{l}30 \cdot 3 \\
30 \cdot 4\end{array}$ & $\begin{array}{l}84-215 \\
94-188\end{array}$ \\
\hline & & \multicolumn{2}{|c|}{ Median } & Range \\
\hline 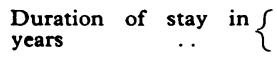 & $\begin{array}{l}\text { I.S.T. } \\
\text { Control }\end{array}$ & \multicolumn{2}{|c|}{$\begin{array}{l}13 \cdot 0 \\
12 \cdot 5\end{array}$} & $\begin{array}{l}1-22 \\
1-22\end{array}$ \\
\hline
\end{tabular}

appreciable difference $(P<0.05)$ between the two groups. All patients were ambulant and on ordinary hospital diet.

The drugs which patients were receiving at the time of the tests are shown in Table II. Twenty-three patients had under-
TABLE II.-Drug Regimen of Insulin Shock Treatment (I.S.T.) Patients and Controls at Time of Tests

\begin{tabular}{|c|c|c|c|c|c|c|}
\hline $\begin{array}{c}\text { No. of } \\
\text { Patients }\end{array}$ & $\begin{array}{c}\text { Chlor- } \\
\text { pro- } \\
\text { mazine } \\
100-200 \\
\text { mg./day }\end{array}$ & $\begin{array}{c}\text { Trifluo- } \\
\text { pera- } \\
\text { zine } \\
5-10 \\
\text { mg./day }\end{array}$ & $\begin{array}{c}\text { Chloral } \\
\text { hydrate } \\
1-2 \mathrm{~g} \cdot / \\
\text { day }\end{array}$ & $\begin{array}{c}\text { Amylo- } \\
\text { barbi- } \\
\text { tone } \\
200-400 \\
\text { mg./day }\end{array}$ & $\begin{array}{c}\text { Pheno- } \\
\text { barbi- } \\
\text { tone } \\
120 \mathrm{mg} . / \\
\text { day }\end{array}$ & $\begin{array}{c}\text { Pheno- } \\
\text { barbi- } \\
\text { tone } \\
120 \mathrm{mg} \text { - } \\
\text { and } \\
\text { pheny- } \\
\text { toin } 150 \\
\text { mg./day }\end{array}$ \\
\hline I.S.T. (10) & 2 & 2 & 3 & 1 & 1 & 1 \\
\hline Control (9) & 3 & 1 & 2 & 2 & - & 1 \\
\hline
\end{tabular}

gone one course, seven had two courses, and one had three courses of insulin shock treatment. Twenty-five rece:ved the treatment in the 10 years 1946-55, and three each in 1936-45 and 1956-65. The mean number of comas in those who had received a single course was 40 (range 15 to 51 ) and in those who had received multiple courses 72 (range 39 to about 150). Details of coma doses were available in half the patients; initial coma dose varied from 80 to 1,000 units of insulin, and final coma dose from 90 to 1,000 units. In nine the initial coma dose was higher than the final, in six the final dose was higher, and in one they were the same.

Twenty-four patients (77\%) had been given one or more courses of E.C.T. during and after insulin shock treatment, and three were later leucotomized. Nine of the controls $(43 \%)$ had received E.C.T. and two were leucotomized. Most patients in both groups had also received courses of sedative drugs and phencthiazine compounds.

\section{Methods}

Standard two-and-a-half-hour glucose tolerance tests were performed in all patients with $50-\mathrm{g}$. of glucose by mouth after overnight fast. Biood was obtained by venepuncture, and glucose was determined by an automated glucose oxidase technique (Faulkner, 1965). Plasma insulin-binding antibody using labelled ox insulin was assayed on fasting samples by the method of Hurn et al. (1970) and plasma insulin levels were estimated by a modification of the double-antibody radioimmunoassay method of Morgan and Lazarow (1S63) in 19 insulin-treated and 18 control patients after overnight fast and at one hour after a $50-\mathrm{g}$. glucose load by mouth.

\section{Results}

\section{Glucose Tolerance Test}

Because of the obviously skew distribution of blood sugar levels within each group at each point in time, median values rather than means were calculated. The median and range for each group at each time are shown in Table III. Comparison of the results obtained at each of these times by the Wilcoxon test showed a significant difference between the insulin-treated and control groups at $60(\mathrm{P}<0.01), 90(\mathrm{P}<0.01)$, and 120 minutes $(P<0.05)$, the insulin-treated group having higher values at each of these times.

In the insulin grcup five patients (three men, two women)

\begin{tabular}{|c|c|c|c|c|c|c|c|c|c|c|}
\hline & & & & & \multirow{2}{*}{ Fasting } & \multicolumn{5}{|c|}{ Time in Minutes after $50 \mathrm{~g}$. Glucose by Mouth } \\
\hline & & & & & & 30 & 60 & 90 & 120 & 150 \\
\hline I.S.T. & . & . & .. & $\cdots$ & $63(52-204)$ & $113(69-252)$ & $129(66-314)$ & $105(25-286)$ & $85(25-250)$ & $64(31-275)$ \\
\hline Control & .. & .. & .. & .. & $63 \cdot 5(45-217)$ & $102(51-318)$ & $89 \cdot 5(37-369)$ & $83.5(31-344)$ & $60(27-308)$ & $58(31-274)$ \\
\hline
\end{tabular}


were found to be "diabetic" (blood sugar $>120 \mathrm{mg} . / 100 \mathrm{ml}$. at two hours), and in the control group one man (Table IV). In

TABLE IV.-Blood Sugar Levels (mg./100 ml.) of 5 Treated and 1 Control Patient who were found to be "Diabetic"

\begin{tabular}{|c|c|c|c|c|c|c|c|c|}
\hline & \multirow{2}{*}{ Age } & \multirow{2}{*}{ Sex } & \multirow{2}{*}{ Fasting } & \multicolumn{5}{|c|}{ Time in Minutes after $50 \mathrm{~g}$. Glucose } \\
\hline & & & & 30 & 60 & 90 & 120 & 150 \\
\hline I.S.T. & $\begin{array}{l}42 \\
39 \\
49 \\
46 \\
55\end{array}$ & $\begin{array}{l}\mathbf{M} \\
\mathbf{M} \\
\mathbf{M} \\
\mathbf{F} \\
\mathbf{F}\end{array}$ & $\begin{array}{r}76 \\
103 \\
121 \\
136 \\
204\end{array}$ & $\begin{array}{l}123 \\
153 \\
173 \\
174 \\
252\end{array}$ & $\begin{array}{l}137 \\
200 \\
241 \\
236 \\
314\end{array}$ & $\begin{array}{l}151 \\
196 \\
242 \\
269 \\
286\end{array}$ & $\begin{array}{l}141 \\
189 \\
250 \\
249 \\
250\end{array}$ & $\begin{array}{l}120 \\
164 \\
275 \\
182 \\
201\end{array}$ \\
\hline Control & 49 & $\mathbf{M}$ & 217 & 318 & 369 & 344 & 308 & 274 \\
\hline
\end{tabular}

none was it possible to trace a family history of diabetes. All three men in the insulin-treated group who were found to be "diabetic" had received two courses of insulin shock treatment.

When these six "diabetic" patients were taken out, the skewness of the distributions was greatly reduced. Since the resulting distributions were about normal, means and standard deviations were calculated for each group at each point in time (Table V). Comparison of the means by Student's $t$ test showed
TABLE VI.-Geometric Means of Plasma Insulin Levels (ng./ml.) in Controls, Treated Patients, and Treated Patients excluding 3 "Diabetics"

\begin{tabular}{|c|c|c|c|}
\hline Group & $\begin{array}{l}\text { No. of } \\
\text { patients }\end{array}$ & $\begin{array}{l}\text { Fasting Plasma } \\
\text { Insulin }\end{array}$ & $\begin{array}{c}1 \text { Hour } \\
\text { Post-glucose } \\
\text { Plasma Insulin }\end{array}$ \\
\hline Control ... & 18 & 0.449 & 1.644 \\
\hline I.S.T. $\left\{\begin{array}{l}\text { All patients } \\
\text { Non-diabetics } \ldots\end{array}\right.$ & $\begin{array}{l}18 \\
15\end{array}$ & $\begin{array}{l}0.348 \\
0.283\end{array}$ & $\begin{array}{l}1.535 \\
1.459\end{array}$ \\
\hline
\end{tabular}

in the diabetic range. Their fasting and one-hour plasma insulin levels were respectively $0.77: 1.65 ; 0.83: 1.45 ; 1.40$ : $3.20 \mathrm{ng} . / \mathrm{ml}$.

When a similar analysis was made excluding these patients (Table VI) the mean fasting plasma insulin level of the depleted insulin-treated group was found to be lower than that of the controls, but this difference just failed to reach statistical significance at the conventional $5 \%$ level $(t=2.00 ; P=0.06)$. There was no significant difference between one-hour levels or mean increase in plasma insulin.

\section{Plasma Insulin and Blood Sugar Levels}

The relation between plasma insulin and blood sugar levels in the two groups was investigated statistically.

TABLE V.-Mean Blood Sugar Levels and Standard Deviations (mg./100 ml.) for 26 Treated and 21 Control Patients (Non-Diabetic)

\begin{tabular}{|c|c|c|c|c|c|c|c|c|c|c|}
\hline & & & & & \multirow{2}{*}{ Fasting } & \multicolumn{5}{|c|}{ Time in Minutes after $50 \mathrm{~g}$. Glucose by Mouth } \\
\hline & & & & & & 30 & 60 & 90 & 120 & 150 \\
\hline I.S.T. & .. & .. & .. & .. & $62(6 \cdot 3)$ & $106(16 \cdot 6)$ & $119(26 \cdot 7)$ & $103(35 \cdot 9)$ & $80(23 \cdot 7)$ & $60(13 \cdot 1)$ \\
\hline Control & .. & .. & .. & .. & $64(10 \cdot 5)$ & $99(19 \cdot 6)$ & $88(29 \cdot 7)$ & $76(27 \cdot 2)$ & $66(22 \cdot 7)$ & $62(17 \cdot 2)$ \\
\hline
\end{tabular}

a significant difference between them at $60(P<0.001), 90$ $(P<0.01)$, and 120 minutes $(P<0.05)$, the insulin-treated group again having the higher values at each of these times.

\section{Plasma Insulin-binding Antibody}

Insulin-binding antibody to bovine insulin was found in two insulin-treated patients and in none of the controls. In one enough was present to interfere with plasma insulin estimation. She was a woman of 43 who had three courses of insulin shock treatment and the largest number of comas in the group. The average coma dose of insulin in her first course was 90 to 110 units and in her last, 14 years later, 500 to 580 units. The other was a 40-year-old man who had the least number of comas (15), during which the coma dose had to be raised from 480 to 840 units. Treatment was finally broken off because of recurrent hypoglycaemic attacks after resuscitation from individual comas.

\section{Plasma Insulin}

Plasma insulin levels were estimated in 19 insulin-treated patients ( 13 men, 6 women) (but one of these had to be excluded because of interference by insulin-binding antibody), and in 18 controls ( 13 men, 5 women). These reduced samples were comparable in age, height, weight, and duration of stay. Results are given as, and calculations are based on, the logarithms of the plasma insulin levels. The geometric mean levels (Table VI) show no significant differences between the two groups fasting, one hour after glucose, or in mean increase in plasma insulin levels.

Three of the insulin-treated patients had blood sugar values
For the fasting blood sugar and fasting (log) plasma insulin levels the correlation coefficients were +0.176 in the control group $(P>0.10)$ and +0.669 in the insulin-treated group $(\mathrm{P}<0.01)$. When, however, the three diabetics were excluded, the correlation coefficient for the depleted insulin-treated group was $+0.266(P>0 \cdot 10)$, which is not significantly different from that of the control group.

In the insulin-treated group the one-hour level of blood sugar was negatively correlated with the increase in plasma insulin $(r=-0.475 ; P<0.05)$-that is, the increase in plasma insulin was small for high values of blood sugar-but this relationship disappeared when the three diabetic patients were removed $(\mathrm{r}=+0.025 ; \mathrm{P}>0.10)$ and is not significantly different from the correlation coefficient for the control group $(r=$ $+0 \cdot 109 ; \mathrm{P}>0 \cdot 10$ ).

The maximum rise in blood sugar was positively correlated with the increase in plasma insulin at one hour in the control group $(\mathrm{r}=+0.585 ; \mathrm{P}<0.02)$ but not in the insulin-treated group ( $\mathrm{r}=-0.307 ; \mathrm{P}>0.10)$, a difference which is significant $(\mathbf{P}<0.01)$. When, however, the three diabetics were excluded the correlation coefficient of the depleted insulin-treated group was $+0.252(P>0 \cdot 10)$, which is not appreciably different from that of the controls.

No other coefficients or comparisons yielded appreciable differences.

\section{Discussion}

That insulin shock treatment might impair glucose tolerance was mooted early. Wilson (1936), who introduced the method to this country, felt this possibility required further investigation. But the vast literature on insulin shock treatment which followed is remarkably sparse on this point. It is also contra- 
dictory. Looney and Cameron (1937) found that glucose tolerance was impaired immediately after a course of shock treatment, Proctor et al. (1944) that it was improved, and Borenz et al. (1949) that it was unchanged. Their interest was determined rather by the search for prognostic factors for insulin shock treatment than by inquiry into the after-effects of giving massive doses of extraneous insulin to non-diabetics. We have, in fact, not been able to find a similar investigation of the long-term repercussions of the treatment on carbohydrate metabolism.

Since the insulin-treated and control groups were closely matched, it seems unlikely that unrecognized physical or mental factors could have accounted for the observed difference in their glucose tolerance. Their treatment history was also similar, so that the effect of drugs like barbiturates which are known to impair glucose tolerance (Hunter et al., 1955) as well as phenothiazine compounds (Thonnard-Neumann, 1968) can be discounted. In any case their effects on carbohydrate metabolism usually remit on cessation of the drugs. Less than onethird of the insulin-treated patients and less than one-half of the controls were receiving sedative or tranquillizing medication at the time of the tests.

Though not statistically significant because of the smallness of the samples, it is noteworthy that five insulin-treated patients were found to have diabetic glucose tolerance tests against only one of the controls. Whether the mechanism of their diabetes is the same as that which in milder form showed itself in impaired glucose tolerance in the group as a whole-both with and without the diabetic patients-compared with that of the controls is a matter for speculation. In this connexion it may be pertinent that McGrath (1950) described a young man who developed diabetes acutely one month after completing a course of insulin shock treatment consisting of 53 comas, 7 fits, and doses of insulin of 70 to 100 units. It will be interesting to observe whether any more of the insulin-treated patients will develop diabetes in the future.

Antibody assay showed that the diminished responsiveness to glucose of the insulin-treated patients was not related to circulating insulin antibody. The possibility of such a mechanism was first suggested by Banting et al. (1938), who found the presence of an insulin-neutralizing substance in the serum globulin fraction in a non-diabetic "schizophrenic" who had received 59 insulin coma treatments with doses of insulin rising from 20 to 1,000 units. Berson et al. (1956) found insulin-binding antibody by the administration of labelled insulin-131I in two out of four recently treated "schizophrenics" attached to the gammaglobulin fraction. Only two patients in the present series were found to have insulin-binding antibody after use of labelled ox insulin, and it was present in only small amounts. Since antibody, if present, would have been stimulated by the injection of ox insulin in the first place, and while there is little definite evidence that antibodies capable of neutralizing endogenous insulin exist, it was not thought to be worth while to search for antibodies reacting specifically with human insulin.

Plasma insulin levels and statistical exploration of the relation between plasma insulin and blood sugar levels showed no difference when the three diabetic insulin-treated patients were excluded. There was a slight suggestion that the insulintreated group had lower fasting plasma insulin levels, and visual comparison (Figs 1 and 2) showed a slightly greater scatter of plasma insulin increase in relation to blood sugar levels in the

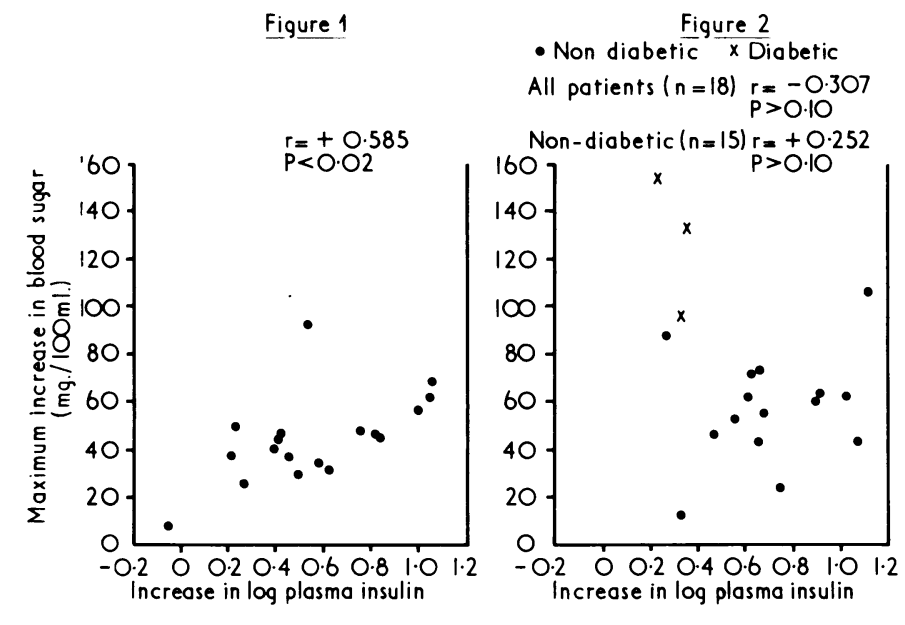

FIG. 1.-Maximum increase in blood sugar and increase in plasma insulin after $50-\mathrm{g}$, glucose load. Control group $(n=18)$.

FIG. 2.- Maximum increase in blood sugar and increase in plasma insulin after $50-\mathrm{g}$. glucose load. Treated group.

insulin-treated group. This may indicate the effect of some unknown factor interfering in varying degrees with the insulin response to glucose stress in the insulin-treated group. This, however, hardly seems sufficient to explain the observed difference in glucose tolerance between the two groups.

It seems more likely that massive doses of extraneous insulin given to non-diabetic subjects may lead to diminished tissue responsiveness to insulin as a persistent after-effect. Perhaps a predisposition to diabetes may be important in this connexion, a possibility which on the limited data concerning patients' family history available it is not possible to exclude.

We thank Dr. T. Hanley, of the Wellcome Foundation, for making this investigation possible; Mr. G. A. Sabey, of the Wellcome Biological Control Laboratories, for performing the glucose estimations; and Drs. J. Barnes and E. Peppercorn for help in collecting specimens and data.

\section{REFERENCES}

Banting, F. G., Franks, W. R., and Gairns, S. (1938). American fournal of Psychiatry, 95, 562.

Berson, S. A., Yalow, R. S., Bauman, A., Rothschild, M. A., and Newerly, K. (1956). Fournal of Clinical Investigation, 35, 170.

Borenz, H. F., Schuster, D. B., and Downey, G. J. (1949). Fournal of Nervous and Mental Diseases, 110, 507.

Bourne, H. (1953). Lancet, 2, 964.

Faulkner, D. E. (1965). Analyst, 90, 736

Hunter, R. A., Merivale, W. H. H., and Smith, A. J. (1955). Lancet, 2

Hurn, B. A. L., Young, B. A., Grahame, A., and Farrant, P. C. (1970). Postgraduate Medical fournal. In press.

Jesner, L., and Ryan V. G. (1941). Shock Treatment in Psychiatry, p. 49. New York, Grune and Stratton.

Looney, J. M., and Cameron, D. E. (1937). Proceedings of the Society for Experimental Biology and Medicine, 37, 253.

McGrath, D. (1950). Fournal of Mental Science, 96, 285

Mayer-Gross, W. (1953). Lancet, 2, 1153

Morgan, C. R., and Lazarow, A. (1963). Diabetes, 12, 115.

Proctor, L. D., Dewan, J. G., and McNeel, B. H. (1944). American fournal of Psychiatry, 100. 652.

Sakel, M. J. (1956). In The Great Physiodynamic Therapies in Psychiatry, edited by A. M. Sackler, M. D. Sackler, R. R. Sackler, and F. Marti-Ibañez, p. 13. New York, Hoeber.

Sargant, W., and Slater, E. (1948). An Introduction to Physical Methods of Treatment in Psychiatry, 2nd ed., p. 20. Edinburgh, Livingstone. Thonnard-Neumann, E. (1968). American fournal of Psychiatry, 124, 978

Wilson, I. G. H. (1936). A Study of Hypoglycaemic Shock Treatment in Schizophrenia, p. 30. London, H.M.S.O. 